Revista Brasil. Bot., V.34, n.3, p.307-319, jul.-set. 2011

\title{
Composição de algas perifíticas (exceto Bacillariophyceae) em distintos substratos naturais de um ambiente semilótico, planície de inundação do Alto Rio Paraná, Brasil ${ }^{1}$
}

\author{
STEFANIA BIOLO ${ }^{2,3}$ e LILIANA RODRIGUES ${ }^{2}$
}

(recebido: 13 de setembro de 2010; aceito: 04 de maio de 2011)

\begin{abstract}
Composition of periphytic algae (except Bacillariophyceae) in different substrates of a semilotic environment from the Upper Paraná River floodplain, Brazil). The purpose of this study was the taxonomy of dominant periphytic algae (except Bacillariophyceae) of three natural substrates, Eichhornia azurea Kunth, Nymphaea amazonum Mart. \& Zucc. and Oxycaryum cubense (Poepp. \& Kunth) Lye in a semi-lotic environment (the Pau Véio backwater) at the Paraná River floodplain. Only those taxa with a frequency of occurrence over $75 \%$ of all samples were considered, except diatoms. Thirty-one taxa were illustrated, measured and identified at species level, a total of 31 taxa were described, distributed in classes: Chlorophyceae (3), Cryptophyceae (1), Cyanobacteria (14 taxa), Zygnemaphyceae (7), Euglenophyceae (2) and Xanthophyceae (4). Twentythree taxa are first taxonomic reports for the Upper Paraná River floodplain: Chamaesiphon investiens Skuja, Geitleribactron subaequale (Geitler) Komárek, Chroococcus limneticus Lemmerm., C. minimus (Keissler) Lemmerm., C. minor (Kütz.) Nägeli, Aphanothece microscopica Nägeli, Phormidium molle (Kütz.) Gomont, Leptolyngbya angustissima (West \& G.S. West) Anagn. \& Komárek, L. foveolarum (Rabenhorst ex Gomont) Anagn. \& Komárek and Pseudanabaena frigida (Fritsch) Anagn. (Cyanobacteria); Characium ensiforme Hermann, C. ornithocephalum A. Braun and Desmodesmus brasiliensis (Bohlin) E. Hegewald (Chlorophyceae); Cosmarium abbreviatum Racib., C. bireme Nordst., C. pseudopyramidatum Lundell, C. subadoxum Grönblad, C. trilobulatum Reinsch, Gonatozygon pilosum Wolle and Staurastrum forficulatum Lundell (Zygnemaphyceae); Trachelomonas hispida (Perty) Stein emend. Deflandre (Euglenophyceae); Cryptomonas tenuis Pascher (Cryptophyceae) and Characiopsis sphagnicola Pascher (Xanthophyceae).
\end{abstract}

Key words - connected pond, floodplain, periphyton, taxonomy

RESUMO - (Composição de algas perifíticas (exceto Bacillariophyceae) em distintos substratos naturais de um ambiente semilótico, planície de inundação do Alto Rio Paraná, Brasil). Constituiu o objetivo deste estudo a taxonomia das algas perifíticas (exceto Bacillariophyceae) dominantes em três substratos naturais, Eichhornia azurea Kunth, Nymphaea amazonum Mart. \& Zucc. e Oxycaryum cubense (Poepp. \& Kunth) Lye, em um ambiente semilótico (Ressaco do Pau Véio), na planície de inundação do Alto Rio Paraná. Considerou-se apenas os táxons com freqüência de ocorrência acima de 75\% das amostras, excetuando-se as diatomáceas. Trinta e um táxons foram descritos, ilustrados e medidos, distribuídos nas classes: Chlorophyceae (3), Cryptophyceae (1), Cyanobacteria (14 taxa), Zygnemaphyceae (7), Euglenophyceae (2) e Xanthophyceae (4). Vinte e três espécies consistiram em primeiros registros taxonômicos para a planície do Alto Rio Paraná: Chamaesiphon investiens Skuja, Geitleribactron subaequale (Geitler) Komárek, Chroococcus limneticus Lemmerm., C. minimus (Keissler) Lemmerm., C. minor (Kütz.) Nägeli, Aphanothece microscopica Nägeli, Phormidium molle (Kütz.) Gomont, Leptolyngbya angustissima (West \& G.S. West) Anagn. \& Komárek, L. foveolarum (Rabenhorst ex Gomont) Anagn. \& Komárek e Pseudanabaena frigida (Fritsch) Anagn. (Cyanobacteria); Characium ensiforme Hermann, C. ornithocephalum A. Braun e Desmodesmus brasiliensis (Bohlin) E. Hegewald (Chlorophyceae); Cosmarium abbreviatum Racib., C. bireme Nordst., C. pseudopyramidatum Lundell, C. subadoxum Grönblad, C. trilobulatum Reinsch, Gonatozygon pilosum Wolle and Staurastrum forficulatum Lundell (Zygnemaphyceae); Trachelomonas hispida (Perty) Stein emend. Deflandre (Euglenophyceae); Cryptomonas tenuis Pascher (Cryptophyceae) e Characiopsis sphagnicola Pascher (Xanthophyceae).

Palavras-chave - lagoa conectada, perifíton, planície alagável, taxonomia

1. Parte da dissertação de mestrado da primeira autora, Programa de Pós-Graduação em Ecologia de Ambientes Aquáticos Continentais, Núcleo de Pesquisas em Limnologia Ictiologia e Aqüicultura, Maringá, PR, Brasil.

2. Universidade Estadual de Maringá, Núcleo de Pesquisas em Limnologia Ictiologia e Aqüicultura, Av. Colombo, 5790, Bloco G-90, 87020-900 Maringá, PR, Brasil.

3. Autora para correspondência: sbiolo@gmail.com

\section{Introdução}

A variabilidade temporal e espacial da comunidade perifítica tem sido atribuída a diversos fatores, como fluxo da água, temperatura, sazonalidade, características limnológicas do ambiente aquático dentre as quais se destacam a concentração de nutrientes e as relações 
bióticas, principalmente a alelopatia e a herbivoria (Wetzel 1983, Lowe \& Pan 1996, Messyasz \& KuczynskaKippen 2006). Messyasz \& Kuczynska-Kippen (2006) ainda ressaltam as características físicas do substrato - a arquitetura específica de cada macrófita e a morfologia estrutural provida por uma macrófita em particular como fatores que estruturam e influenciam a dinâmica da comunidade perifítica em substratos naturais, juntamente à sazonalidade e às características ambientais.

As alterações na composição taxonômica da comunidade perifítica podem ter um grande significado ecológico, tanto no fluxo de energia, na ciclagem de nutrientes dentre outros processos inerentes aos ecossistemas em planícies de inundação (McCormick et al. 1998). A composição taxonômica das algas é uma valiosa ferramenta para o conhecimento da integridade biótica e auxilia no desenvolvimento de diagnósticos das causas diretas e indiretas dos problemas ambientais (Stevenson \& Smol 2003). Assim, grupos predominantes de algas na comunidade perifítica em determinados ecossistemas podem refletir as características bióticas e abióticas prevalentes no ambiente aquático (Pip \& Robinson 1981, Felisberto et al. 2001). Desta forma, é de fundamental importância o conhecimento taxonômico das algas perifíticas em estudos ecológicos. Para a planície de inundação do Alto Rio Paraná, a informação taxonômica das algas perifíticas, em literatura, consta em apenas duas publicações. Fonseca \& Rodrigues (2005a) realizaram o levantamento das cianobactérias de dois ambientes lênticos, a partir da análise da comunidade perifítica presente no substrato Eichhornia azurea Kunth. Biolo \& Rodrigues (2010) descreveram, na comunidade perifítica da macrófita Ricciocarpus natans (L.) Corda, os táxons pertencentes às classes Xanthophyceae e Euglenophyceae em um ambiente semilótico da planície.

Outros registros de algas na comunidade perifítica para a planície de inundação do Alto Rio Paraná podem ser encontrados em listagens de trabalhos de cunho ecológico (Rodrigues \& Bicudo 2001, Fonseca \& Rodrigues 2005b, Algarte et al. 2006). O presente trabalho traz uma abordagem complementar de uma série de estudos ecológicos acerca das algas perifíticas em distintos substratos naturais neste ambiente. Para o presente levantamento taxonômico foram selecionados os táxons ocorrentes em $75 \%$ dos substratos e períodos amostrados Excetuando-se os membros da classe Bacillariophyceae, grupo predominante na planície do Alto Rio Paraná (Rodrigues \& Bicudo 2001) e alvo de estudos anteriores, buscou-se proceder a descrição dos táxons pertencentes às demais classes para as quais a taxonomia ainda é ausente ou incipiente para a planície.
Com base na relativa escassez de informações, este trabalho visou aprofundar o conhecimento taxonômico das algas perifíticas na planície de inundação do Alto Rio Paraná. Além disso, contribuiu na ampliação da distribuição geográfica das espécies, podendo vir a auxiliar na elucidação de questões ecológicas importantes em estudos futuros.

\section{Material e métodos}

O presente estudo foi desenvolvido no Ressaco do Pau Véio (figura 1), que consiste num ambiente semilótico com conexão permanente ao Rio Paraná. Os ambientes semilóticos são caracterizados pela baixa velocidade da água, geralmente inferior àquela da calha do Rio Paraná. O sentido da corrente d'água pode inverter-se nestes ambientes, fenômeno comumente observado principalmente no período de águas altas (cheias). Como as lagoas fechadas, os ambientes semilóticos possuem sua dinâmica temporal relacionada às alterações dos níveis hidrométricos do Rio Paraná (Thomaz et al. 1997). O Ressaco do Pau Véio situa-se na Ilha Mutum, na planície de inundação do Alto Rio Paraná, Município de Porto Rico, PR, na divisa dos Estados do Paraná e Mato Grosso $\left(22^{\circ} 44^{\prime} \mathrm{S}-53^{\circ} 15^{\prime} \mathrm{W}\right)$. Apresenta área de 3,0 hectares, comprimento de $1.146,4 \mathrm{~m}$ e profundidade média de $1,8 \mathrm{~m}$. A vegetação ripária compreende espécies arbustivas e herbáceas, dentre estas se destacam Croton spp. e Inga uraguensis Hook. \& Arn. com uma transição gradual para o ambiente aquático a partir da presença de diversos estandes de macrófitas aquáticas, compostos principalmente por espécies emergentes, como Eichhornia azurea Kunth e Nymphaea amazonum Mart. \& Zucc., e espécies submersas, como Egeria najas Planch. e E. densa Planch. e a epífita Oxycaryum cubense (Poepp. \& Kunth) Lye.

As coletas da comunidade perifítica foram realizadas trimestralmente entre junho de 2008 e março de 2009. Os substratos naturais para coleta do material perifítico consistiram de pecíolos de macrófitas aquáticas em estágio adulto (conforme recomendação de Schwarzbold 1990) das seguintes espécies e grupos ecológicos, de acordo com Irgang et al. (1984): Eichhornia azurea (emergente) e Nymphaea amazonum (flutuante fixa), além do caule de Oxycaryum cubense (epífita). Em O. cubense foi também amostrada a bainha foliar envolvida na região do caule. A seleção dos substratos deu-se em razão da presença em um mesmo banco multiespecífico sob condições ambientais similares, e em todos os períodos amostrados. Além de apresentarem características morfoestruturais semelhantes, buscou-se a padronização das metodologias de coleta e, principalmente suprir a ausência de estudos da comunidade perifítica englobando os dois últimos substratos citados na planície do Alto Rio Paraná.

Após o corte da região do pecíolo submerso com tesoura, os substratos coletados aleatoriamente de cada macrófita $(n=3)$, na região litorânea do ambiente, foram acondicionados em frascos de Wheaton $(150 \mathrm{~mL})$ borrifados 


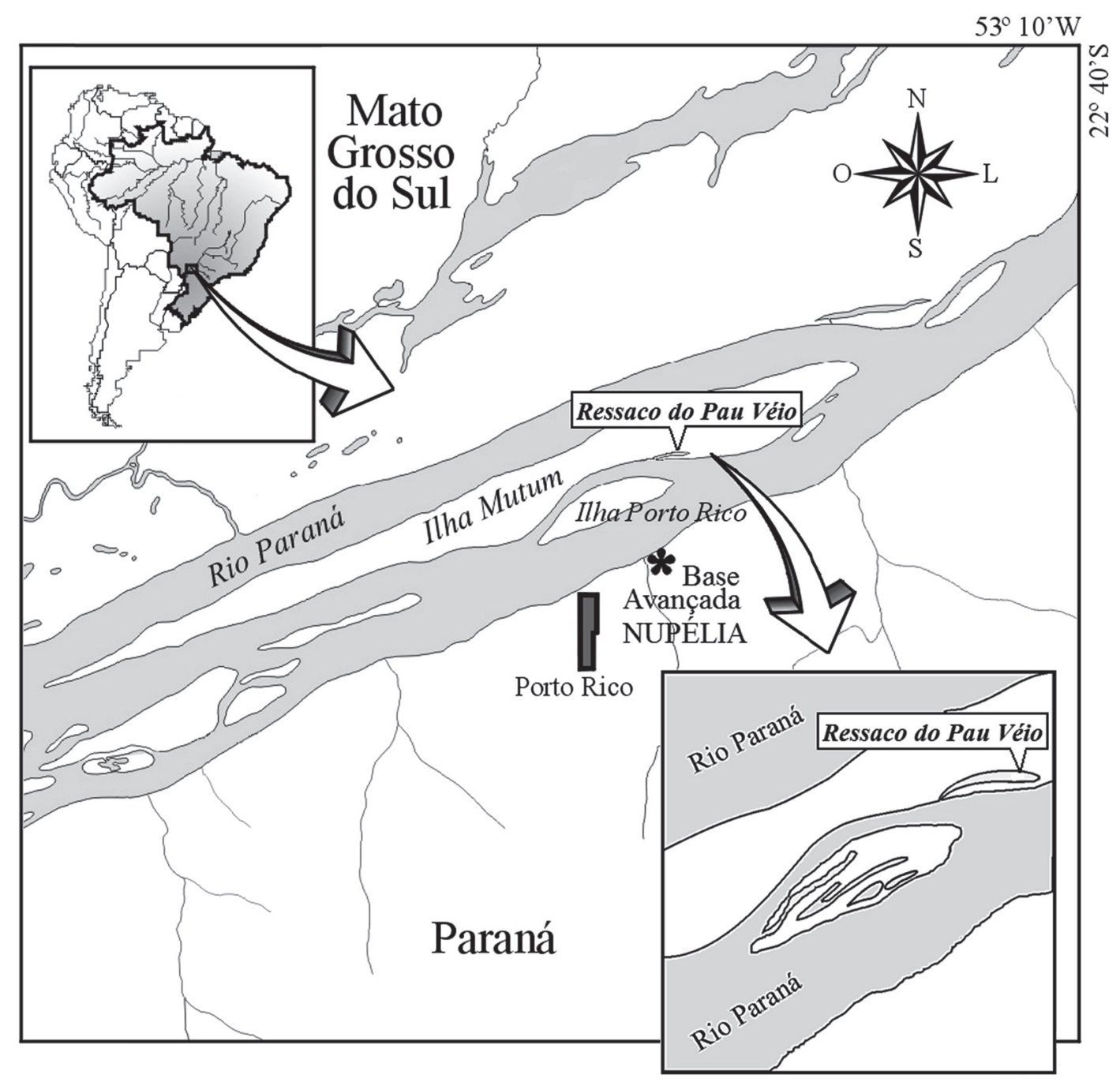

Figura 1. Localização do Ressaco do Pau Véio na planície de inundação do Alto Rio Paraná, Paraná, Brasil.

Figure 1. Localization of Pau Véio backwater at the Paraná River Floodplain, Paraná State, Brazil.

com água destilada e mantidos em caixa de isopor com gelo. Posteriormente foram transportados ao laboratório e para remoção do material perifítico procedeu-se a raspagem dos pecíolos, caules e bainha foliar a utilização de lâmina de aço revestida em papel alumínio e pincel fino e macio com o auxílio de jatos de água destilada. O material designado à análise qualitativa foi fixado em solução Transeau na proporção 1:1 conforme recomendado por Bicudo \& Menezes (2006). As amostras da comunidade perifítica de cada substrato encontram-se depositadas no Herbário da Universidade Estadual de Maringá (HUEM) sob a numeração 18.384 a 18.410 .

A análise taxonômica das algas perifíticas procedeuse por meio da preparação de lâminas temporárias, em microscopia óptica binocular com ocular micrometrada e câmara clara acoplada, nos aumentos de 400x e 1000x (Bicudo \& Menezes 2006). Foram considerados somente os táxons encontrados na análise qualitativa que recorreram também na análise quantitativa, sendo que o presente trabalho faz parte de um projeto maior que visou o conhecimento ecológico da comunidade. Assim, para fins de adequação metodológica entre as análises qualitativas e quantitativas, as espécies encontradas raramente na análise qualitativa foram consideradas táxons acidentais na comunidade perifítica e não foram inclusos na análise da comunidade. As descrições taxonômicas foram restritas somente aos táxons identificados em nível específico, excetuando-se os representantes da classe Bacillariophyceae. Além disso, a taxonomia no presente trabalho foi realizada apenas para as espécies com frequência de ocorrência acima de $75 \%$ das amostras, ou seja, que recorreram em quase todos os períodos e substratos amostrados; dado que os táxons comuns constituíram, em sua grande maioria, de espécies não identificadas em nível específico e de diatomáceas (não englobadas no presente estudo).

Os táxons encontrados foram medidos e identificados com base na bibliografia clássica e regional. Os sistemas de 
classificação adotados compreenderam Komárek \& Anagn. (1986) e Anagn. \& Komárek (1988), para Cyanobacteria, e Round (1965, 1971, apud Bicudo \& Menezes 2006), recomendado por Bicudo \& Menezes (2006), para os demais grupos. A distribuição geográfica foi baseada em trabalhos de cunho taxonômico da comunidade perifítica na planície de inundação do Alto Rio Paraná até o ano de 2011.

\section{Resultados e discussão}

A comunidade de algas perifíticas dominantes nos distintos substratos e períodos amostrados no Ressaco do Pau Véio correspondeu a 31 táxons. Estes táxons distribuíram-se nas classes Chlorophyceae (3 espécies), Cryptophyceae(1), Cyanobacteria(14), Zygnemaphyceae (7), Euglenophyceae (2) e Xanthophyceae (4) e ocorreram nos distintos substratos períodos de amostragem (tabela 1).

\section{CYANOBACTERIA}

\section{CHAMAESIPHONACEAE}

Chamaesiphon investiens Skuja, Nova Acta Regiae Soc. Sci. Upsal., ser. 4, 18(3): 45. 1964.

Figura 2

Células geralmente agregadas de forma paralela e densa, fixas ao substrato perpendicularmente, formando uma camada quase contínua de células; células alongadas, levemente ovóides a cilíndricas, raramente arcuadas, arredondadas ou acuminadas nas extremidades, base levemente estreitada, às vezes com a presença de haste e almofada mucilaginosa, conteúdo celular azul-esverdeado pálido, pseudobainha fina, incolor se presente, exocitos solitários, arredondados ou levemente poligonal-arredondados; célula $6,8-12 \mu \mathrm{m}$ compr., 2-5 $\mu \mathrm{m}$ larg.

Ocorrência em literatura na planície de inundação do Alto Rio Paraná: primeira citação.

Komárek e Anagn. (1999) discutem a presença da pseudobainha, muitas vezes aparentemente ausente. Quando totalmente ausente, os representantes remetem ao gênero Geitleribactron Komárek. Os indivíduos encontrados apresentaram, na maioria das vezes, a pseudobainha envolvendo as células e, desta forma, foram identificados no presente gênero.

Geitleribactron subaequale (Geitler) Komárek, Pl. Syst. Evol. 123: 265, 278. 1975.

Figura 3

Células solitárias ou formando colônias, sésseis, organizadas formando uma camada de células azulesverdeada sobre o substrato, células retas ou levemente arcuadas, cilíndricas, levemente achatadas na base, extremidades arredondadas, raro grânulos solitários, bainha ausente, conteúdo mais ou menos homogêneo, cinza-esverdeado pálido a azul-esverdeado intenso, divisão celular por fissão celular na região mediana da célula, raro na extremidade ou base; célula 2-6 $\mu \mathrm{m}$ compr., 1-1,5 $\mu \mathrm{m}$ larg.

Ocorrência em literatura na planície de inundação do Alto Rio Paraná: primeira citação.

\section{CHROOCOCCACEAE}

Chroococcus limneticus Lemmerm., Beih. Bot. Centralbl. 76: 153.1898.

Figura 4

Colônias muitas vezes tabulares com 4-8, bainha mucilaginosa distinta ou difluente, não lamelada, incolor, células subesféricas ou esféricas após a divisão, divisão celular em 2 direções, raramente em 3, com ou sem bainha, conteúdo celular azul-esverdeado, aerótopos ausentes; célula 5-6 $\mu \mathrm{m}$ larg.

Ocorrência em literatura na planície de inundação do Alto Rio Paraná: primeira citação.

Chroococcus minimus (Keissler) Lemmerm., Ark. Bot. 2(2): 102. 1904.

Figura 5

Colônias microscópicas, esféricas ou irregulares, formando grupos de 2-4 células, células verde-azuladas, inseridas em mucilagem, não lamelada, hialina, difluente, células subesféricas ou esféricas após a divisão, conteúdo celular homogêneo, aerótopos ausentes; células 1-2 $\mu \mathrm{m}$ larg.

Ocorrência em literatura na planície de inundação do Alto Rio Paraná: primeira citação.

Chroococcus minor (Kütz.) Nägeli, Gatt. Einzell. Alg.: 46. 1849.

Figura 6

Colônias gelatinosas, formando grupos de 2-4 células irregularmente arranjadas, amorfas, verde-azuladas ou verdes escuras, mucilagem delicada, espessa, difluente, transparente, células subesféricas; células 2-4 $\mu \mathrm{m}$ diâm., colônias 9-14 ㅆm diâm.

Ocorrência em literatura na planície de inundação do Alto Rio Paraná: primeira citação.

\section{MERISMOPEDIACEAE}

Aphanocapsa parasitica (Kütz.) Komárek \& Anagn., Preslia 67: 15. 1995.

Figura 7 
Tabela 1. Ocorrência $(+)$ dos táxons dominantes de algas perifíticas nos distintos substratos naturais $(\mathrm{E}=$ Eichhornia azurea; $\mathrm{N}=$ Nymphaea amazonum; $\mathrm{O}=$ Oxycaryum cubense) do Ressaco do Pau Véio no período de estudo (junho/2008 a março/2009).

Table 1. Occurrence $(+)$ of dominant taxa of periphytic algae in different natural substrates $(\mathrm{E}=$ Eichhornia azurea; $\mathrm{N}=$ Nymphaea amazonum; $\mathrm{O}=$ Oxycaryum cubense) of the Pau Véio backwater during study period (June 2008 to March 2009).

\begin{tabular}{|c|c|c|c|c|c|c|c|c|c|c|c|c|}
\hline \multirow{2}{*}{$\begin{array}{l}\text { Período } \\
\text { Substrato }\end{array}$} & \multicolumn{3}{|c|}{$\begin{array}{l}\text { JUN } \\
2008\end{array}$} & \multicolumn{3}{|c|}{$\begin{array}{c}\text { SET } \\
2008\end{array}$} & \multicolumn{3}{|c|}{$\begin{array}{l}\text { NOV } \\
2008\end{array}$} & \multicolumn{3}{|c|}{$\begin{array}{l}\text { MAR } \\
2009\end{array}$} \\
\hline & $\mathrm{E}$ & $\mathrm{N}$ & $\mathrm{O}$ & $\mathrm{E}$ & $\mathrm{N}$ & $\mathrm{O}$ & E & $\mathrm{N}$ & $\mathrm{O}$ & $\mathrm{E}$ & $\mathrm{N}$ & $\mathrm{O}$ \\
\hline \multicolumn{13}{|l|}{ CYANOBACTERIA } \\
\hline Aphanocapsa parasitica (Kütz.) Komárek \& Anagn. & + & + & + & + & + & + & + & + & + & + & + & + \\
\hline Aphanothece microscopica Nägeli & + & + & & & & + & + & + & + & + & + & \\
\hline Chamaesiphon investiens Skuja & + & & & + & + & & & + & + & + & + & + \\
\hline Chroococcus limneticus Lemmerm. & + & + & & & + & + & + & + & + & + & + & + \\
\hline Chroococcus minor (Kütz.) Nägeli & + & + & & + & + & + & + & + & + & + & + & + \\
\hline Chroococcus minimus (Keissler) Lemmerm. & + & + & + & + & & + & + & + & + & + & & + \\
\hline Geitleribactron subaequale (Geitler) Komárek & + & + & & + & + & + & + & + & + & & + & \\
\hline Leibleinia epiphytica (Hieron.) Anagn. \& Komárek & + & + & + & + & + & + & + & + & + & + & + & + \\
\hline $\begin{array}{l}\text { Leptolyngbya angustissima (West e G. S. West) Anagn. } \\
\text { \& Komárek }\end{array}$ & + & + & & + & + & + & + & + & + & + & + & + \\
\hline $\begin{array}{l}\text { Leptolyngbya foveolarum (Rabenhorst ex Gomont) Anagn. } \\
\text { \& Komárek }\end{array}$ & + & + & + & + & & & + & + & & + & + & + \\
\hline Leptolyngbya perelegans (Lemmerm.) Anagn. \& Komárek & + & + & + & + & + & + & + & + & + & + & + & + \\
\hline Phormidium molle (Kütz.) Gomont & + & + & & + & + & + & + & + & + & + & + & + \\
\hline Pseudanabaena frigida (Fritsch) Anagn. & + & & & & + & + & + & + & + & + & + & + \\
\hline Pseudanabaena moniliformis Komárek \& Kling & + & & & & + & + & + & + & + & + & + & + \\
\hline \multicolumn{13}{|l|}{ CHLOROPHYCEAE } \\
\hline Characium ensiforme G. S. West & + & + & & & + & & + & + & + & + & + & + \\
\hline Characium ornithocephalum A. Braun & + & + & + & & & + & + & + & + & + & & + \\
\hline Desmodesmus brasiliensis (Bohlin) E. Hegewald & + & + & + & + & + & + & + & + & + & + & + & + \\
\hline \multicolumn{13}{|l|}{ ZYGNEMAPHYCEAE } \\
\hline Cosmarium abbreviatum Racib. & + & & + & + & + & + & + & + & + & + & + & + \\
\hline Cosmarium bireme Nordst. & + & + & + & + & + & + & + & & & + & + & \\
\hline Cosmarium pseudopyramidatum Lundell & & + & + & + & + & + & + & & + & + & + & + \\
\hline Cosmarium subadoxum Grönblad & + & + & & + & + & + & + & & & + & + & + \\
\hline Cosmarium trilobulatum Reinsch & + & + & & + & + & + & + & + & + & + & & \\
\hline Gonatozygon pilosum Wolle & & + & & + & + & + & + & + & + & + & & + \\
\hline Staurastrum forficulatum Lundell & & & & + & + & + & + & + & + & + & + & + \\
\hline \multicolumn{13}{|l|}{ EUGLENOPHYCEAE } \\
\hline Trachelomonas hispida (Perty) Stein emend. Deflandre & + & & + & + & & + & + & + & & + & + & + \\
\hline Trachelomonas sp. & + & + & + & + & + & + & + & + & + & + & + & + \\
\hline \multicolumn{13}{|l|}{ CRYPTOPHYCEAE } \\
\hline Cryptomonas tenuis Pascher & + & & + & + & & + & + & + & & + & + & + \\
\hline \multicolumn{13}{|l|}{ XANTHOPHYCEAE } \\
\hline Characiopsis acuta (A. Braun) Borzi & + & + & & + & + & + & + & + & + & + & + & + \\
\hline Characiopsis aquilonaris Skuja & + & + & + & & + & + & + & + & + & + & + & + \\
\hline Characiopsis elegans Ettl & + & + & & & & + & + & + & + & + & + & + \\
\hline Characiopsis sphagnicola Pascher & + & + & + & & & + & + & + & + & + & + & + \\
\hline
\end{tabular}




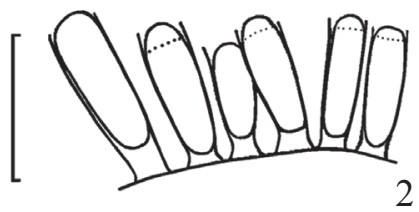
2

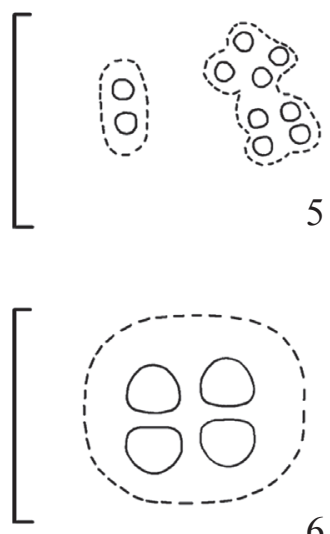

6

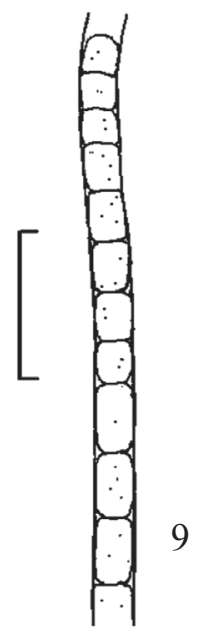

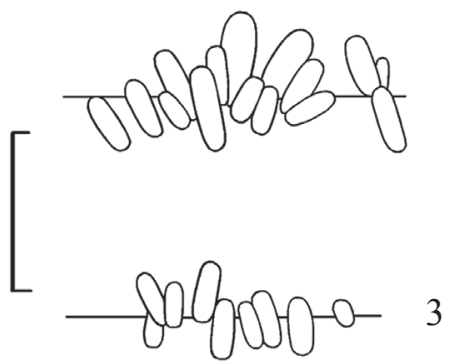
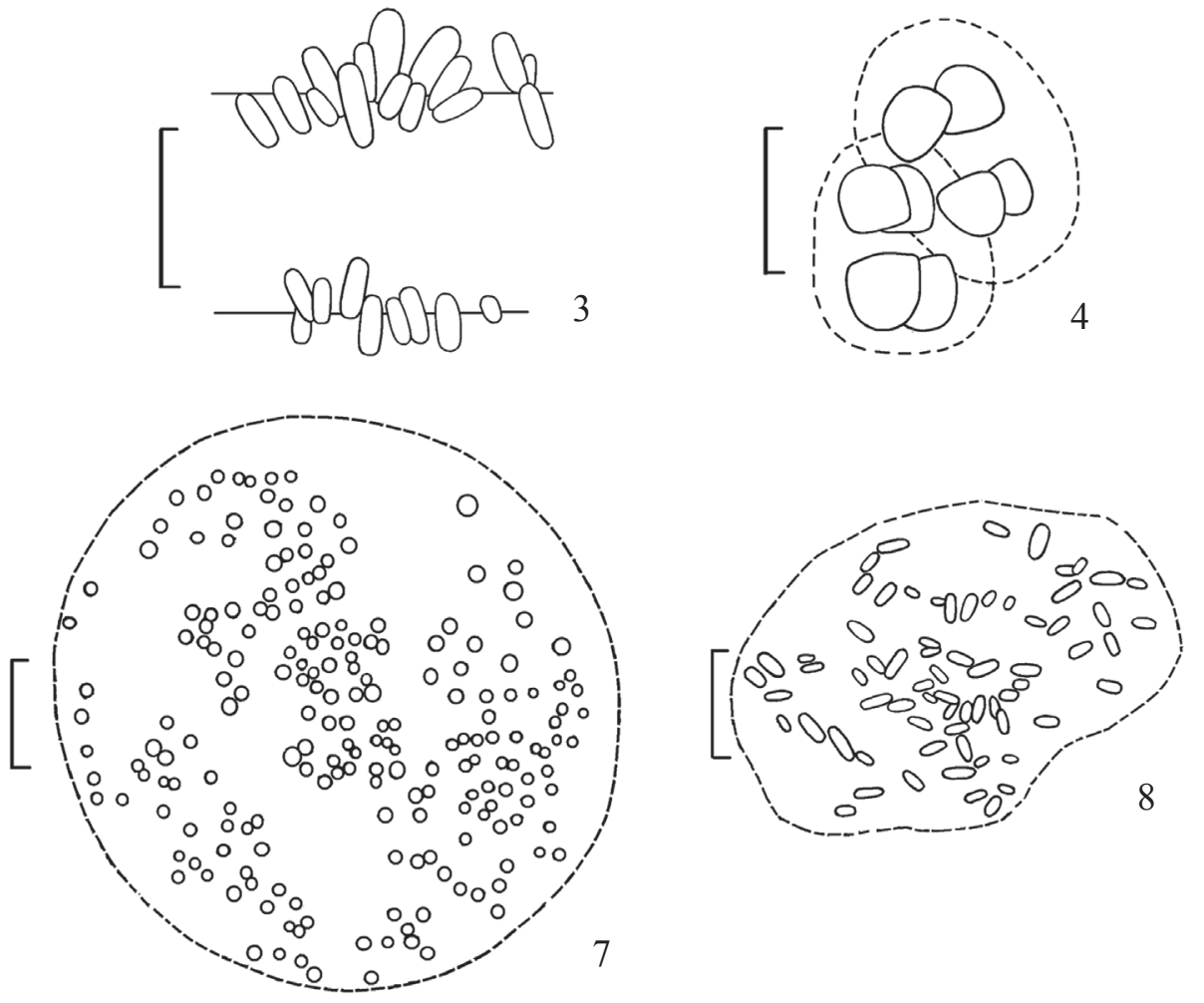

7
4
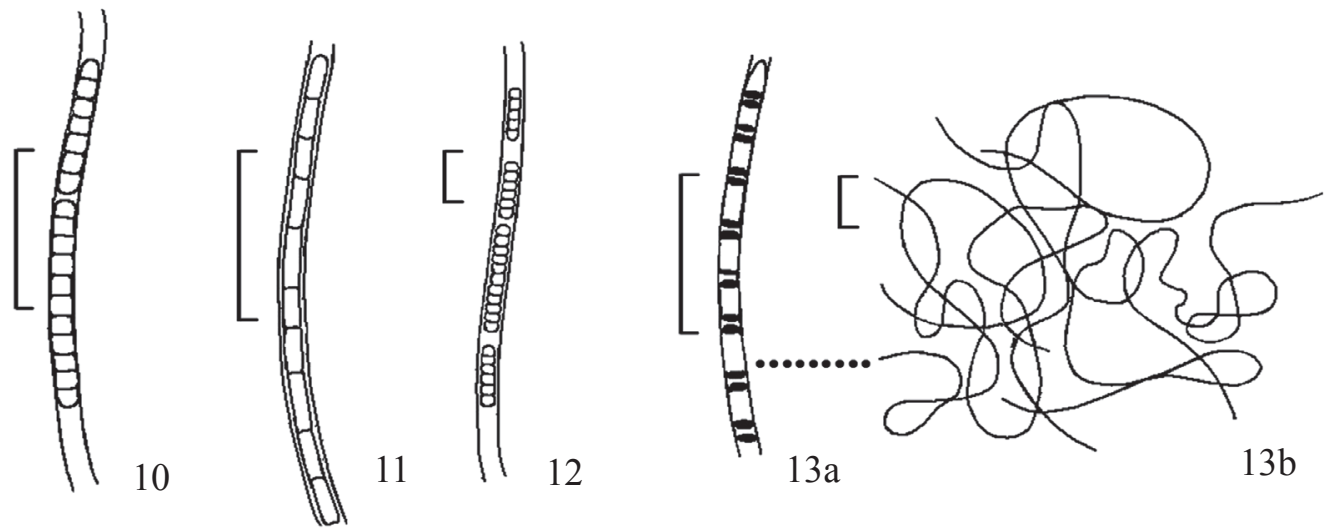

Figuras 2-13. Algas perifíticas em distintos substratos naturais da planície do Alto Rio Paraná. 2. Chamaesiphon investiens. 3. Geitleribactron subaequalis. 4. Chroococcus limneticus. 5. Chroococcus minimus. 6. Chroococcus minor. 7. Aphanocapsa parasitica. 8. Aphanothece microscopica. 9. Phormidium molle. 10. Leibleinia epiphytica. 11. Leptolynbya angustissima. 12. Leptolyngbya foveolarum. 13a. Leptolyngbya perelegans. 13b. Aspecto do emaranhado de filamentos. Barra $=10 \mu \mathrm{m}$.

Figures 2-13. Periphytic algae in distinct natural substrates from the Upper Paraná River floodplain. 2. Chamaesiphon investiens. 3. Geitleribactron subaequalis. 4. Chroococcus limneticus. 5. Chroococcus minimus. 6. Chroococcus minor. 7. Aphanocapsa parasitica. 8. Aphanothece microscopica. 9. Phormidium molle. 10. Leibleinia epiphytica. 11. Leptolynbya angustissima. 12. Leptolyngbya foveolarum. 13a. Leptolyngbya perelegans. 13b. Aspect of filaments. Bar $=10 \mu \mathrm{m}$. 
Colônias arredondadas, microscópicas, mais ou menos densa, mucilagem incolor; células esféricas; 1-2 $\mu \mathrm{m}$ larg.

Ocorrência em literatura na planície de inundação do Alto Rio Paraná: Fonseca \& Rodrigues (2005a); listado em trabalho ecológico (Algarte et al. 2006).

\section{SYNECHOCOCCACEAE}

Aphanothece microscopica Nägeli, Gatt. Einzell. Alg., S. 59. 1849.

Figura 8

Colônias mucilaginosas, azul-esverdeadas, inicialmente microscópicas, esféricas a oval, mucilagem mais ou menos delimitada, posteriormente amorfa, macroscópica, mucilagem irregular e difluente, células ovais a cilíndricas, densamente arranjadas, às vezes com bainha mucilaginosa individual, incolor; células 1-3,5 $\mu \mathrm{m}$ compr., $0,5-1 \mu \mathrm{m}$ larg.

Ocorrência em literatura na planície de inundação do Alto Rio Paraná: primeira citação.

\section{PHORMIDIACEAE}

Phormidium molle (Kütz.) Gomont, Ann. Sci. Nat., Bot., ser. 7, 16: 159, 163, 1893.

Figura 9

Filamentos levemente curvados, bainha fina, difluente, indistinta, incolor, tricomas constritos, não atenuado nos pólos, célula apical arredondada, sem caliptra; células isodiamétricas, conteúdo celular com grânulos, parede celular sem grânulos e translúcida, aerótopos ausentes; 2,5-9 $\mu \mathrm{m}$ compr., 2-3 $\mu \mathrm{m}$ larg.

Ocorrência em literatura na planície de inundação do Alto Rio Paraná: primeira citação.

\section{PSEUDANABAENACEAE}

Leibleinia epiphytica (Hieronymus) Anagn. \& Komárek, Algol. Stud. 50-53: 394. 1988.

Figura 10

Filamentos solitários, curvos, bainha incolor, tricomas não atenuados, constritos, septos não granulosos, células mais ou menos isodiamétricas, célula apical arredondada; células 1-2 $\mu \mathrm{m}$ compr., 0,5-1,5 $\mu \mathrm{m}$ larg.

Ocorrência em literatura na planície de inundação do Alto Rio Paraná: Lagoa Clara e Lagoa das Garças (Fonseca \& Rodrigues 2005a); listado em trabalho ecológico, como Lyngbya epiphytica Hieron. (Rodrigues \& Bicudo 2001).
Leptolyngbya angustissima (West \& G. S. West) Anagn. \& Komárek, Algol. Stud. 50-53: 390. 1988.

Figura 11

Filamentos curvos, bainha conspícua, fina, incolor, difluente, tricomas levemente constritos, não granulados, não atenuados, célula apical arredondada, sem caliptra; células cilíndricas, conteúdo homogêneo, 2,5-5 $\mu \mathrm{m}$ compr., 0,8-2 $\mu \mathrm{m}$ larg.

Ocorrência em literatura na planície de inundação do Alto Rio Paraná: primeira citação.

Komárek \& Anagn. (2005) apontam para a semelhança entre esta espécie e L. tenuis (Gomont) Anagn. \& Komárek. Segundo estes autores, L. tenuis corresponde a uma espécie de hábito edáfico, enquanto L. angustissima é de hábito aquático continental. Assim, apesar dos limites métricos dos indivíduos encontrados estarem de acordo com os descritos para L. tenuis, consideramos os indivíduos presentes identificados como L. angustissima .

Leptolyngbya foveolarum (Rabenhorst ex Gomont) Anagn. \& Komárek, Algol. Stud. 50-53: 391. 1988.

Figura 12

Filamentos curvados, às vezes retos, formando massas ou tufos, bainha fina, conspícua, incolor, difluente, tricomas distintamente constrito, não granulados, célula apical arredondada, sem caliptra, células isodiamétricas, conteúdo celular homogêneo com grânulos esparsamente distribuídos; células 1-2 $\mu \mathrm{m}$ compr., 1-2 $\mu \mathrm{m}$ larg.

Ocorrência em literatura na planície de inundação do Alto Rio Paraná: primeira citação.

Leptolyngbya perelegans (Lemmerm.) Anagn. \& Komárek, Algol. Stud. 50-53: 392. 1988.

Figura 13a-b

Filamentos solitários, retos, bainha conspícua, incolor, homogênea, tricomas não atenuados, não constritos, septos com um grânulo em cada lado da parede celular, célula apical cilíndrica, sem caliptra, células cilíndricas; células 2-5 $\mu \mathrm{m}$ compr., 0,4-1,4 $\mu \mathrm{m}$ larg.

Ocorrência em literatura na planície de inundação do Alto Rio Paraná: Lagoa das Garças (Fonseca \& Rodrigues 2005a); listado em trabalho ecológico (Algarte et al. 2006).

Pseudanabaena frigida (Fritsch) Anagn., Preslia 73: 359-375. 2001.

Figura 14

Tricomas não atenuado nos pólos, bainha difluente, fortemente constrito, translúcido, células cilíndricas, 
arredondadas ou aproximadamente isodiamétricas, tão longas quanto largas ou 2 vezes mais longas que largas, célula apical cônico-arredondada, caliptra ausente, presença de aerótopos subpolar; células 1-4 $\mu \mathrm{m}$ compr., $1-1,5 \mu \mathrm{m}$ larg.

Ocorrência em literatura na planície de inundação do Alto Rio Paraná: primeira citação.

Pseudanabaena moniliformis Komárek \& Kling, Algol. Stud. 61: 27. 1991.

Figura 15

Tricomas solitários, retos, curtos, constritos, célula apical arredondada, sem espessamento; células cilíndricas, 1,5-2 vezes mais longas do que largas, conteúdo celular homogêneo, presença de aerótopos subpolar; ausência de grânulos na parede celular; células 2-4 $\mu \mathrm{m}$ compr., 1-1,6 $\mu \mathrm{m}$ larg.

Ocorrência em literatura na planície de inundação do Alto Rio Paraná: Lagoa Clara e Lagoa das Garças (Fonseca \& Rodrigues 2005a).

\section{CHLOROPHYCEAE}

\section{CHLOROCOCCACEAE}

Characium ensiforme Hermann in Rabenhorst, Beitr. Kenntn. U. Verbr. Alg. 26. 1863.

Figura 16

Indivíduos pediculados, pedículo almofadado, curto, dispostos mais ou menos perpendiculares no substrato; célula fusiforme assimétrica, margens assimétricas, uma delas pouco convexa, a outra mais acentuadamente convexa, ápice agudo, extremidade arredondada; parede celular delicada, cloroplasto 1, laminar, parietal, pirenóide 1, central; 11-14 $\mu \mathrm{m}$ compr. (com pedículo), pedículo 1,5-2 $\mu \mathrm{m}$ compr.; 2-2,5 $\mu \mathrm{m}$ larg.

Ocorrência em literatura na planície de inundação do Alto Rio Paraná: primeira citação taxonômica; listado em trabalho ecológico (Algarte et al. 2006).

Characium ornithocephalum A. Braun, Alg. Unicell. 42. 1855.

Figura 17

Indivíduos pediculados, dispostos perpendiculares a inclinados no substrato, pedículo almofadado, longo; célula falciforme, moderadamente assimétrica, margens mais ou menos uniformemente convexas, ápice acuminado, extremidade pontiaguda; parede celular delicada, cloroplasto 1, laminar, parietal, pirenóide 1, central; 17-28 $\mu \mathrm{m}$ compr. (com pedículo), pedículo 5,57,7 $\mu \mathrm{m}$ compr., 3-5,5 $\mu \mathrm{m}$ larg.
Ocorrência em literatura na planície de inundação do Alto Rio Paraná: primeira citação taxonômica; listado em trabalho ecológico (Algarte et al. 2006).

\section{SCENEDESMACEAE}

Desmodesmus brasiliensis (Bohlin) E. Hegewald, Algol. Stud. 96: 7. 2000.

Figura 18

Cenóbios formados por 2-4 células dispostas linearmente, células oblongo-elípticas, presença de costelas ao longo de todo o comprimento, 1 espinho em cada lado das costelas; 8-23 $\mu \mathrm{m}$ compr.; 7,5$19 \mu \mathrm{m}$ larg.

Ocorrência em literatura na planície de inundação do Alto Rio Paraná: primeira citação.

\section{ZYGNEMAPHYCEAE}

DESMIDIACEAE

Cosmarium abbreviatum Racib., Pam. Akad. Umiej. Krakowie Mat.-Przyr. 10: 83. 1885.

Figura 19

Células pequenas, 1,1 vezes mais longas que largas, constrição mediana profunda, seno mediano linear, fechado, semicélulas transversalmente angular-ovaladas, com 5 lados, margem lateral inferior divergente, reta, para um ângulo médio arredondado, às vezes levemente pronunciado, margem superior convergente, retas a quase retas, para um ápice relativamente amplo, truncado, parede celular lisa, cloroplasto 1, pirenóide 1; células 9-18 $\mu \mathrm{m}$ compr.; 8,5-16 $\mu \mathrm{m}$ larg.; istmo 2-5,5 $\mu \mathrm{m}$.

Ocorrência em literatura na planície de inundação do Alto Rio Paraná: primeira citação taxonômica; listado em trabalho ecológico (Rodrigues \& Bicudo 2001, Algarte et al. 2006).

Prescott et al. (1981) apresenta a variedade típica da espécie com a forma geral das semicélulas de 5 lados, ângulos laterais arredondados ou, às vezes, mamilados.

Cosmarium bireme Nordst., Vidensk. Meddel. Dansk Naturhist. Foren. Kjobenhavn 1869(14/15): 212. 1870.

Figura 20

Células pequenas, aproximadamente tão longas quanto largas, constrição mediana profunda, seno mediano linear, semicélulas angular-elípticas, ápice achatado, presença de papila na região mediana da semicélula, claramente visível em todas as vistas, vista apical elíptica, parede celular lisa ou finamente pontuada, 

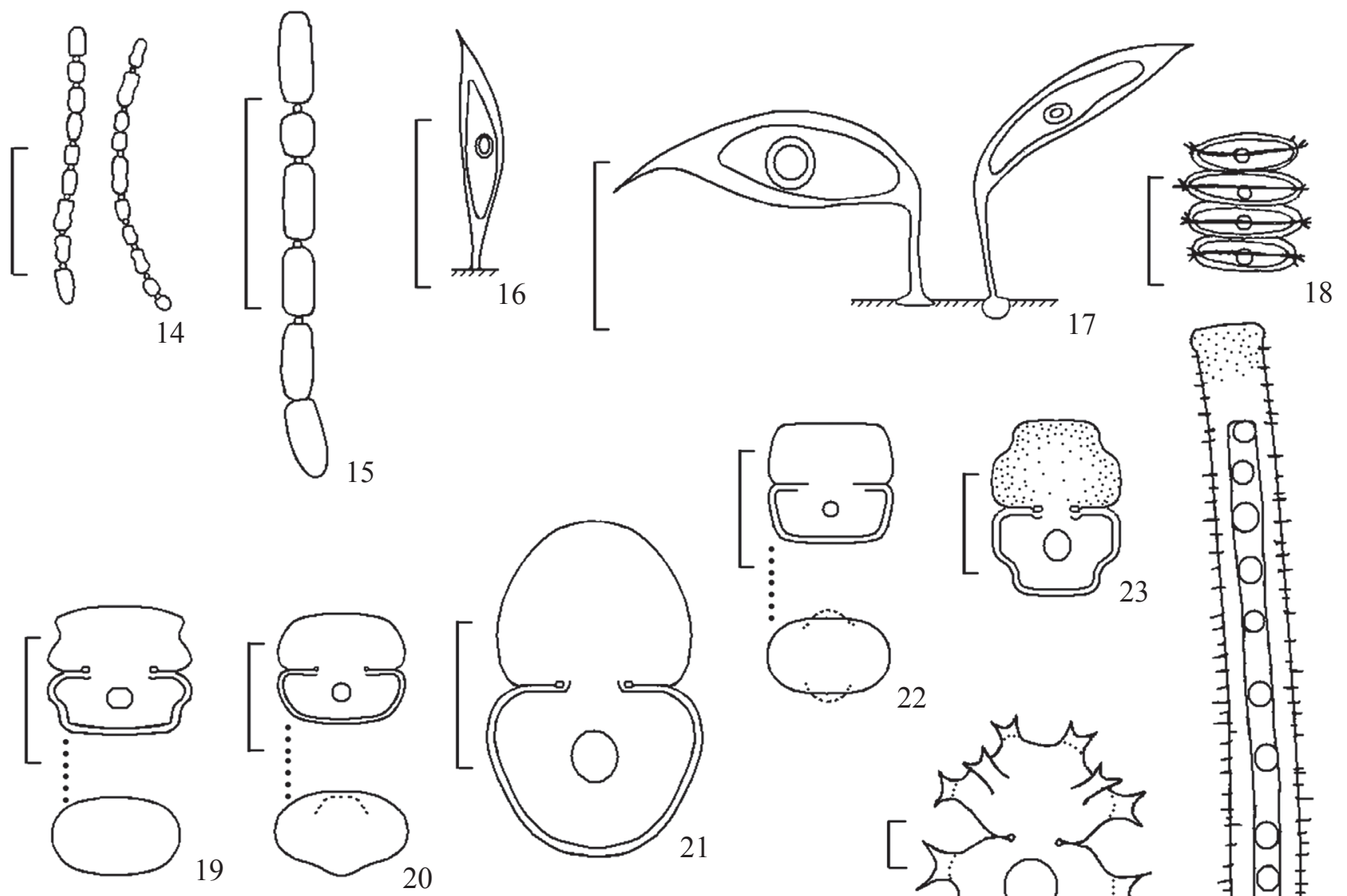

15
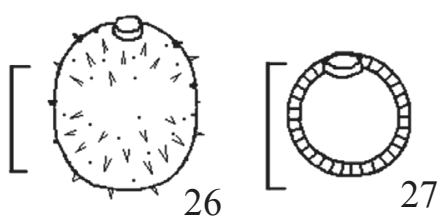

27

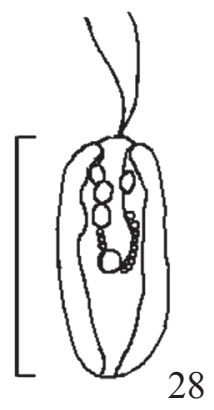

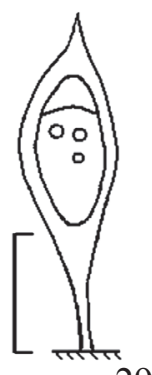

29
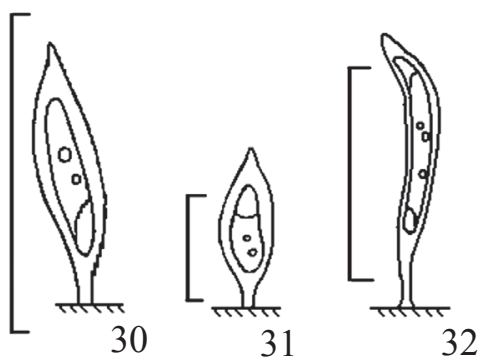

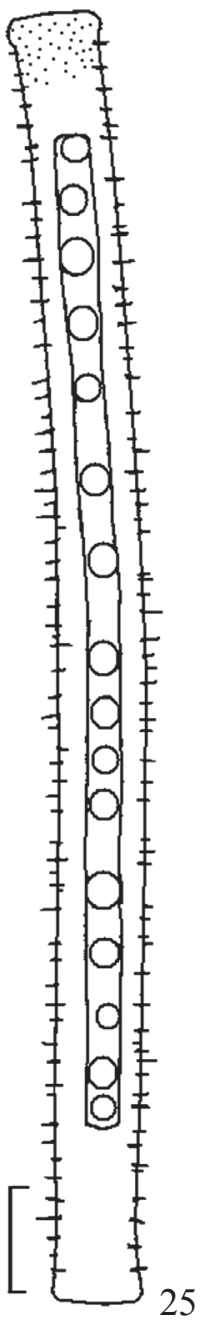

Figuras 14-32. Algas perifíticas em distintos substratos naturais da planície do Alto Rio Paraná. 14. Pseudanabaena frigida. 15. Pseudanabaena moniliformis. 16. Characium ensiforme. 17. Characium ornithocephalum. 18. Desmodesmus brasiliensis. 19. Cosmarium abbreviatum. 20. Cosmarium bireme. 21. Cosmarium pseudopyramidatum. 22. Cosmarium subadoxum. 23. Cosmarium trilobulatum. 24. Staurastrum forficulatum. 25. Gonatozygon pilosum. 26. Trachelomonas hispida. 27. Trachelomonas sp. 28. Cryptomonas tenuis. 29. Characiopsis acuta. 30. Characiopsis aquilonaris. 31. Characiopsis elegans. 32. Characiopsis sphagnicola. Barra $=10 \mu \mathrm{m}$.

Figures 14-32. Periphytic algae in distinct natural substrates from the Upper Paraná River floodplain. 14. Pseudanabaena frigida. 15. Pseudanabaena moniliformis. 16. Characium ensiforme. 17. Characium ornithocephalum. 18. Desmodesmus brasiliensis. 19. Cosmarium abbreviatum. 20. Cosmarium bireme. 21. Cosmarium pseudopyramidatum. 22. Cosmarium subadoxum. 23. Cosmarium trilobulatum. 24. Staurastrum forficulatum. 25. Gonatozygon pilosum. 26. Trachelomonas hispida. 27. Trachelomonas sp. 28. Cryptomonas tenuis. 29. Characiopsis acuta. 30. Characiopsis aquilonaris. 31. Characiopsis elegans. 32. Characiopsis sphagnicola. $\mathrm{Bar}=10 \mu \mathrm{m}$. 
cloroplasto 1, pirenóide 1; células 10-12 $\mu \mathrm{m}$ compr., 11$12 \mu \mathrm{m}$ larg., istmo 3-4 $\mu \mathrm{m}$.

Ocorrência em literatura na planície de inundação do Alto Rio Paraná: primeira citação.

Cosmarium pseudopyramidatum Lundell, Nova Acta Regiae Soc. Sci. Upsal., ser. 3, 8(2): 41. 1871.

Figura 21

Células 1,3 vezes mais compridas que largas, constrição mediana profunda, seno mediano linear, dilatado no ápice, semicélula piramidal, margens laterais convergentes para um ápice estreito, truncado, parede celular lisa a pontuada, cloroplasto 1 , pirenóide $1 ; 18$ $25 \mu \mathrm{m}$ compr.; 14-19 $\mu \mathrm{m}$ larg.; istmo 4-5 $\mu \mathrm{m}$.

Ocorrência em literatura na planície de inundação do Alto Rio Paraná: primeira citação taxonômica; listado em trabalho ecológico (Rodrigues \& Bicudo 2001, Algarte et al. 2006).

Cosmarium subadoxum Grönblad, Meddel. Soc. Fauna Fl. Fenn. 10: 268. 1934.

Figura 22

Células pequenas, tão longas quanto largas, constrição mediana profunda, seno mediano estreito, linear, semicélulas transversalmente retangulares, ângulos basais amplamente arredondados, margens laterais convexas, ápice truncado, tão amplo quanto a base da semicélula, leve intumescência na região mediana da semicélula, parede celular lisa, vista apical arredondada, com uma leve intumescência na região mediana em cada lado; 10-11 $\mu \mathrm{m}$ compr., 10-11 $\mu \mathrm{m}$ larg., istmo 3-4 $\mu \mathrm{m}$.

Ocorrência em literatura na planície de inundação do Alto Rio Paraná: primeira citação.

Cosmarium trilobulatum Reinsch, Abh. Senckenberg. Naturf. Ges. 6(118). 1866.

Figura 23

Células 1,1-1,5 vezes mais compridas que largas, constrição mediana profunda, seno mediano linear, dilatado no ápice, semicélula subtrapeziforme, 3-lobada, lobo apical truncado, margens laterais levemente convexas, parede celular lisa a finamente pontuada, cloroplasto 1, pirenóide 1; 12-18 $\mu \mathrm{m}$ compr.; 11-13 $\mu \mathrm{m}$ larg.; istmo 2,5-3 $\mu \mathrm{m}$.

Ocorrência em literatura na planície de inundação do Alto Rio Paraná: primeira citação taxonômica; listado em trabalho ecológico (Algarte et al. 2006).
Staurastrum forficulatum Lundell, Nova Acta Regiae Soc. Sci. Upsal., ser. 3, 8(22): 66. 1871.

Figura 24

Células médias a grandes, tão longas quanto largas ou um pouco mais longas que largas, constrição mediana profunda, seno estreito, linear, posteriormente abrindose de forma ampla, semicélulas subtrapeziformes ou subelípticas, margem apical truncada, 2 processos apicais proeminentes, bífidos, ângulos laterais levemente pronunciados, ornamentados com 2 espinhos robustos, divergentes, superpostos; 38-41 $\mu \mathrm{m}$ compr.; 35-37,5 $\mu \mathrm{m}$ larg. (sem processos); istmo 9-9,5 $\mu \mathrm{m}$.

Ocorrência em literatura na planície de inundação do Alto Rio Paraná: primeira citação.

\section{GONATOZYGACEAE}

Gonatozygon pilosum Wolle, Bull. Torrey Bot. Club 9(3): 27.1882.

Figura 25

Célula 10,1-17,5 vezes mais comprida que larga, célula subcilíndrica, margens laterais retas, ápice truncado; parede celular aparentemente lisa, espinhos cobrindo toda a célula, cloroplasto 1, laminar, axial, pirenóides 4-8; 105-142 $\mu \mathrm{m}$ compr.; 6-14 $\mu \mathrm{m}$ larg.

Ocorrência em literatura na planície de inundação do Alto Rio Paraná: primeira citação taxonômica; listado em trabalho ecológico (Rodrigues \& Bicudo 2001).

\section{EUGLENOPHYCEAE}

\section{EUGLENACEAE}

Trachelomonas hispida (Perty) Stein emend. Deflandre, Rev. Gén. Bot. 38: 650. 1926.

Figura 26

Lóricas amplamente elipsoidais, castanhoamarelada a castanho-arroxeada, cobertas por espinhos pequenos, delgados, cônicos, acuminados, irregularmente distribuídos, poro anular com ou sem colarinho, pontuações bastante espaçadas; 11-15 compr.; 6-13 $\mu \mathrm{m}$ larg., espessamento anelar 1,5-2 $\mu \mathrm{m}$ larg.

Ocorrência em literatura na planície de inundação do Alto Rio Paraná: primeira citação taxonômica; Ressaco do Pau Véio (var. duplex, Biolo \& Rodrigues 2010); listado em trabalho ecológico (Algarte et al. 2006).

\section{Trachelomonas sp.}

Figura 27

Lórica esférica, espessamento anelar presente, colarinho ausente, ou muito baixo; parede lisa ou pontuada, amarelada a castanho, grãos de paramido 
vários, discóides; 7-14 $\mu \mathrm{m}$ diâm., espessamento anelar 2-2,5 $\mu \mathrm{m}$ diâm.

Os indivíduos encontrados poderiam ser identificados em duas espécies distintas como Trachelomonas volvocina (Ehrenberg) Ehrenberg ou T. volvocinopsis Swirenko. Ocorre sobreposição nos limites métricos entre estas duas espécies, sendo que a diferença entre $T$. volvocina e $T$. volvocinopsis reside no número de plastídios e presença de pirenóides (Tell \& Conforti 1986), caracteres não observados nos indivíduos do presente levantamento. Desta forma, optou-se por identificar os indivíduos encontrados apenas em nível genérico (Biolo \& Rodrigues 2010). Para a planície de inundação do Alto Rio Paraná, os registros dos dois táxons encontram-se em Oliveira et al. (1994), Jati \& Train (1993) e Jati \& Train (1994). Em trabalhos de cunho ecológico, foram reportados em listagens de espécies na comunidade fitoplanctônica, $T$. volvocinopsis (Train et al. 2000).

\section{CRYPTOPHYCEAE}

\section{CRYPTOMONADACEAE}

Cryptomonas tenuis Pascher, Süsswasserflora 2: 105. 1913

Figura 28

Células isoladas, pólo posterior levemente afilado, arredondado, dois cromatóforos laterais, pirenóides ausentes; $10-12 \mu \mathrm{m}$ compr., 4-5 $\mu \mathrm{m}$ larg.

Ocorrência em literatura na planície de inundação do Alto Rio Paraná: primeira citação.

\section{XANTHOPHYCEAE}

\section{CHARACIOPSIDACEAE}

Characiopsis acuta (A. Braun) Borzi, Stud. Algol. 2: 153. 1895.

Figura 29

Indivíduo pediculado, célula 3,1-3,3 vezes mais comprida que larga, célula subfusiforme, levemente arqueada, ápice apiculado, pólo basal afilado em pedículo longo, disco de fixação pequeno; cromoplastos 2, parietais, laminares, lobados; células 25-28 $\mu \mathrm{m}$ compr. (com pedículo), 8-9 $\mu \mathrm{m}$ larg., pedículo 5-5,5 $\mu \mathrm{m}$ compr.

Ocorrência em literatura na planície de inundação do Alto Rio Paraná: Ressaco do Pau Véio (Biolo \& Rodrigues 2010).

Characiopsis aquilonaris Skuja, Nova Acta Regiae Soc. Sci. Upsal., ser. 4, 18: 333. 1964.

Figura 30

Indivíduo quase séssil, célula 2,3-3 vezes mais comprida que larga, célula subfusiforme a falcada, um dos lados convexo e o outro reto a levemente côncavo, ápice acuminado, pólo basal afilado em pedículo quase ausente, pouco distinto; cromoplasto 1, parietal, laminar; células 6-8 $\mu \mathrm{m}$ compr., 2-3,5 $\mu \mathrm{m}$ larg.

Ocorrência em literatura na planície de inundação do Alto Rio Paraná: Ressaco do Pau Véio (Biolo \& Rodrigues 2010); listado em trabalho ecológico (Rodrigues \& Bicudo 2001, Algarte et al. 2006).

Characiopsis elegans Ettl, Bot. Not. 109: 430. 1956. Figura 31

Indivíduo séssil, célula 3-5 vezes mais comprida que larga, subfusiforme a subfalcada, lados convexos, às vezes desiguais, ápice acuminado a apiculado-arqueado, pólo basal afilado em pedículo quase ausente, pouco distinto, com ou sem disco de fixação, cromoplasto 1, parietal, laminar; células 10-15 $\mu \mathrm{m}$ compr. (com pedículo), 2-5 $\mu \mathrm{m}$ larg.

Ocorrência em literatura na planície de inundação do Alto Rio Paraná: Ressaco do Pau Véio (Biolo \& Rodrigues 2010).

Characiopsis sphagnicola Pascher in Rabenhorst, Krypt.-Fl. Deutschland. 11: 763. 1939.

Figura 32

Indivíduo séssil, célula 8-8,8 vezes mais comprida que larga, subfalcada, ápice acuminado, pólo basal afilado em pedículo quase ausente, com ou sem disco de fixação, cromoplasto 1, parietal, laminar; células 1226,5 $\mu \mathrm{m}$ compr. (com pedículo), 1,5-3 $\mu \mathrm{m}$ larg.

Ocorrência em literatura na planície de inundação do Alto Rio Paraná: primeira citação.

A despeito da dominância dos táxons do presente estudo nos substratos e períodos amostrados, estes perfazem uma fração muito baixa em relação ao número total de táxons da comunidade perifítica, representando 7,6\% do total de 406 táxons registrados no Ressaco do Pau Véio. Entretanto, a maior parte da comunidade foi constituída por táxons raros a comuns, predominantemente diatomáceas e espécies não identificadas em nível específico, como os representantes dos gêneros Oedogonium spp. e Spyrogira spp., bem como algumas clorofíceas. Tais táxons necessitam da verificação dos diversos estágios do ciclo reprodutivo das espécies, muitas vezes não observado em sua totalidade em amostras fixadas. Ainda, a prevalência de baixos níveis hidrométricos e a ausência de inundações na planície do Alto Rio Paraná, fato observado para o ano amostrado de 2008 
(Roberto et al. 2009), provavelmente influenciam a dominância de determinados táxons na comunidade de algas perifíticas (Leandrini et al. 2008). Buscou-se, desta forma, enfatizar o registro dos táxons dominantes, através da sua taxonomia, que ocorreram, em termos de frequência de ocorrência, em todos os períodos e substratos amostrados.

Apesar da ampla distribuição das cianobactérias, é necessário um minucioso trabalho na identificação e delimitação geográfica de suas espécies, o que evidencia a importância dos levantamentos florísticos em regiões tropicais (Branco et al. 2003). Cyanobacteria consiste em um dos principais grupos em termos de riqueza e abundância na comunidade perifítica dos ambientes da planície do Alto Rio Paraná (Rodrigues \& Bicudo 2001, Fonseca \& Rodrigues 2005, Algarte et al. 2006, 2009).

O presente trabalho registrou 23 novos registros taxonômicos para a planície de inundação do Alto Rio Paraná: Chamaesiphon investiens, Geitleribactron subaequale, Chroococcus limneticus, C. minimus, C. minor, Aphanothece microscopica, Phormidium molle, Leptolyngbya angustissima, L. foveolarum e Pseudanabaena frigida (Cyanobacteria); Characium ensiforme, C. ornithocephalum e Desmodesmus brasiliensis (Chlorophyceae); Cosmarium abbreviatum, C. bireme, C. pseudopyramidatum, C. subadoxum, $C$. trilobulatum, Gonatozygon pilosum e Staurastrum forficulatum (Zygnemaphyceae); Trachelomonas hispida (Euglenophyceae); Cryptomonas tenuis (Cryptophyceae) e Characiopsis sphagnicola (Xanthophyceae). Este fato denota a insuficiência dos estudos taxonômicos das algas perifíticas, particularmente para a planície de inundação do Alto Rio Paraná.

Agradecimentos - As autoras agradecem ao CNPq (Conselho Nacional de Pesquisa) e à Capes (Coordenação de Aperfeiçoamento de Pessoal de Nível Superior) pelo apoio científico, e ao Nupélia (Núcleo de Pesquisas em Limnologia, Ictiologia e Aquicultura) pelo auxílio no desenvolvimento do trabalho. Ainda, agradecemos ao Dr. Carlos Eduardo de Mattos Bicudo pela revisão do trabalho. Esta pesquisa é parte do Projeto PELD (Pesquisas Ecológicas de Longa Duração/CNPq, “A Planície Alagável do Alto Rio Paraná" - Site 6).

\section{Referências bibliográficas}

ALGARTE, V.M., MORESCO, C. \& RODRIGUES, L. 2006. Algas do perifíton de distintos ambientes na planície de inundação do Alto Rio Paraná. Acta Scientiarum 28:243-251.
ALGARTE, V.M., SIQUEIRA, N.S., MURAKAMI, E.A. \& RODRIGUES, L. 2009. Effects of hydrological regime and connectivity on the interannual variation in taxonomic similarity of periphytic algae. Brazilian Journal of Biology 69:609-616.

ANAGNOSTIDIS, K. \& KOMÁREK, J. 1988. Modern approach to the classification system of Cyanophytes, 3: Oscillatoriales. Algological Studies 80:327-472.

BICUDO, C.E.M. \& MENEZES, M. 2006. Gênero de algas de águas continentais do Brasil. Chave para identificação e descrição. Rima, São Carlos.

BIOLO, S. \& RODRIGUES, L. 2010. New records of Xanthophyceae and Euglenophyceae in the periphytic algal community from a neotropical river floodplain, Brazil. Algological Studies 135:61-81.

BRANCO, L.H.Z., MOURA, A.N., SILVA, A.C. \& BITTENCOURT-OLIVEIRA, M.C. 2003. Biodiversidade e considerações biogeográficas das Cyanobacteria de uma área de manguezal do Estado de Pernambuco, Brasil. Acta Botanica Brasilica 17:585-596.

FELISBERTO, S.A., RODRIGUES, L. \& LEANDRINI, J.A. 2001. Chloroccoccales registradas na comunidade perifitica no reservatório Corumbá, Estado de Goiás, Brasil, antes e após o represamento das águas. Acta Scientiarium 23:275-282.

FONSECA, I.A. \& RODRIGUES, L. 2005a. Cianobactérias perifíticas em dois ambientes lênticos da planície de inundação do Alto Rio Paraná, PR, Brasil. Revista Brasileira de Botânica 28:821-834.

FONSECA, I.A. \& RODRIGUES, L. 2005b. Comunidade de algas perifíticas em distintos ambientes da planície de inundação do Alto Rio Paraná. Acta Scientiarum 27:21-28.

IRGANG, B.E., PEDRALLI, G. \& WALCHTER, J.I. 1984. Macrófitos aquáticos da Estação Ecológica do Taim, Rio Grande do Sul, Brasil. Roessleria 6:395-404.

JATI, S. \& TRAIN, S. 1993. Representantes do gênero Trachelomonas Ehrenberg, de duas lagoas da ilha Porto Rico, município de Porto Rico, Paraná, Brasil. Unimar 15:37-51.

JATI, S. \& TRAIN, S. 1994. Euglenaceae pigmentadas de ambientes lênticos da Ilha Porto Rico, Município de Porto Rico, Paraná Brasil. Iheringia 45:117-142.

KOMÁREK, J. \& ANAGNOSTIDIS, K. 1986. Modern approach to the classification system of Cyanophytes, 2: Chroococcales. Algological Studies 43:157-226.

KOMÁREK， J. \& ANAGNOSTIDIS, K. 1999. Cyanoprokaryota I Teil Chroococcales. In Süßwasserflora von Mitteleuropa (H. Ettl, G. Gärtner, H. Heynig, \& D. Mollenhauer, eds.). Gustav Fischer Verlag, Stuttgart, v.19/1, p.1-548.

KOMÁREK, J. \& ANAGNOSTIDIS, K. 2005. Cyanoprokaryota II. Teil, $2^{\text {nd }}$ Part: Oscillatoriales. In Süsswasserflora von Mitteleuropa (B. Büdel, L. Krienitz, G. Gärtner \& M. Schagerl, eds.). Elsevier/Spektrum, Heidelberg, v.19/2, p.1-759 
LEANDRINI, J.A., FONSECA, I.A., \& RODRIGUES, L., 2008. Characterization of habitats based on algal periphyton biomass in the Upper Paraná River floodplain. Revista Brasileira de Biologia 68:503-509.

LOWE, R.L. \& PAN, Y., 1996. Periphyton patterns in lakes. In Algal ecology, freshwater benthic ecosystems (R.J. Stevenson, M.L. Bothwell \& R.L. Lowe, eds.). Academic Press, San Diego, p.57-77.

MESSYASZ, B. \& KUCZYNSKA-KIPPEN, N. 2006. Periphytic algal communities: a comparison of Typha angustifolia L. and Chara tomentosa L. beds in three shallow lakes (West Poland). Polish Jounal of Ecology 54:15-27.

MCCORMICK, P.V., SHUFORD III, R.B.E., BACKUS, J.G. \& KENNEDY, W.C. 1998. Spatial and seasonal patterns of periphyton biomass and productivity in the northern Everglades, Florida, USA. Hydrobiologia 362:185-208.

OLIVEIRA, M.D., TRAIN, S. \& RODRIGUES, L.C. 1994. Levantamento preliminar do fitoplâncton de rede (exceto Zygnemaphyceae) do Rio Paraná, no município de Porto Rico, Paraná, Brasil. Unimar 16:155-174.

PIP, E. \& ROBINSON, G.G.C. 1981. A comparision of algal periphyton composition on eleven species of submerged macrophytes. Hydrobiological Bulletin 18:109-118.

PRESCOTT, G.W., CROASDALE, H.T., VINYARD, W.C. \& BICUDO, C.E.M. 1981. A synopsis of North American desmids; Part II. Desmidiaceae: Placodermae. Section 3. In Desmidiales (G.W. Prescott, ed.). University Nebraska Press, Lincoln, p.1-720.
RODRIGUES, L. \& BICUDO, D.C. 2001. Similarity among periphyton algal communities in a lentic-lotic gradient of the upper Paraná River floodplain, Brazil. Brazilian Journal of Botany 24:235-248.

SCHWARZBOLD, A., 1990. Métodos ecológicos aplicados ao estudo do perifíton. Acta Limnologica Brasiliensia 3:545-592.

STEVENSON, R.J. \& SMOL, J.P. 2003. Use of algae in environmental assessments. In Freshwater algae of North America, ecology and classification (J.D. Wehr \& Sheath, R.G., eds.). Academic Press, San Diego, p.775-804.

TELL, G. \& CONFORTI, V.T.D. 1986. Euglenophyta pigmentadas de la Argentina. Bibliotheca Phycologica 75:163-182.

THOMAZ, S.M., ROBERTO, M.C. \& BINI, L.M. 1997. Caracterização limnológica dos ambientes aquáticos e influência dos níveis fluviométricos. In A planície de inundação do Alto Rio Paraná: aspectos físicos, químicos, biológicos e socioeconômicos (A.E.A.M. Vazzoler, A.A. Agostinho, \& N.S. Hahn, eds.). Eduem, Maringá, p.73-102.

TRAIN, S., OLIVEIRA, M.D. \& QUEVEDO, M.T. 2000. Dinâmica sazonal da comunidade fitoplanctônica de um canal lateral (Canal Cortado) do Alto Rio Paraná. Acta Scientiarum 22:389-399.

WETZEL, R.G. 1983. Opening remarks. In Periphyton of freshwater ecosystems (R.G. Wetzel, ed.). Dr. W. Junk Publishers, The Netherlands, p.339-346. 
